Gut, 1975, 16, 57-61

\title{
Posterior mediastinal venous masses in patients with portal hypertension
}

\author{
P. J. A. MOUlT, D. W. WAite, AND R. DiCK \\ From the Departments of Medicine and Radiology, Royal Free Hospital, London
}

SUMMARY Of 304 consecutive splenic venograms performed for suspected portal hypertension, oesophageal collateral veins were filled in 145 . In seven patients massively dilated paraoesophageal collaterals were visible on the plain chest radiograph as a retrocardiac posterior mediastinal mass. Erect and supine radiographs have been compared in four patients, and the Valsalva and Mueller manoeuvres performed in one patient. The size of the masses was unchanged by these procedures, which were therefore of no value in differential diagnosis. The mass was still present immediately after portocaval anastomosis in one patient, but in another is no longer seen on radiographs taken seven years postoperatively. All seven patients also had submucosal oesophageal varices and therefore the barium swallow remains the most useful study to clarify the nature of a retrocardiac mass. Correct identification of pseudotumoural venous collaterals may avoid unnecessary further investigation.

The commonest changes seen on the chest radiograph in patients with portal hypertension are dilatation of the azygos vein and widening of the left paravertebral shadow due to lateral displacement of the pleural reflection by the dilated hemiazygos vein (Doyle, Read, and Evans, 1961). Mediastinal pseudotumours due to aneurysmal dilatation of the azygos vein (Sayer, Parmley, and Morris, 1954), hemiazygos vein (Campbell and Baruch, 1960; Leigh, Abbott, Rogers, and Gay, 1954), and paraoesophageal collaterals (Jonsson and Rian, 1970) have also been reported.

We have reviewed 304 consecutive splenic venograms performed for suspected portal hypertension. Oesophageal collaterals had been filled on 145 occasions. In seven of these patients a plain chest radiograph shows a lower posterior mediastinal mass, which corresponds to dilated portosystemic collaterals on the splenic venogram. These seven patients form the subject of this report. Other patients with large oesophageal or paraoesophageal collaterals have been excluded when no mass is seen on the plain radiograph, either because the veins overlie the vertebral column in the anterior projection, or because they cannot be distinguished from the shadow of the descending aorta or the mediastinal pleural reflection.

Received for publication 17 October 1974.

\section{Patients}

The group comprises four males and three females with ages ranging from 29 to 69 years. The table shows the aetiology and duration of known portal hypertension, in each patient. In patients 1-6 the serum albumin concentration was normal, suggesting that liver function was well preserved; serum transaminase concentrations were also normal. Biochemical data are not now available for patient 7 , but liver histology was examined in every patient and showed inactive cirrhosis.

Four patients have undergone laparotomy. Patients 1 and 6 had end-to-side portocaval anastomoses performed successfully. In patient 7 the portal vein was found to be thrombosed and an ileorenal shunt was established. Patient 3 was submitted to open liver biopsy. Patients 4-7 have since died, but necropsy was performed only in no. 7: dilated paraoesophageal veins were found measuring up to $8 \mathrm{~mm}$ in diameter.

\section{Radiological Findings}

In each patient on a postero-anterior or anteroposterior chest radiograph a homogenous opacity with smooth margins is visible through the cardiac shadow (figs 1 and 2). On the lateral chest film of patient 1 the opacity has a lobulated appearance 


\begin{tabular}{|c|c|c|c|c|c|c|c|c|}
\hline Patient & Age & Sex & Diagnosis ${ }^{\mathbf{l}}$ & 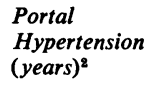 & $\begin{array}{l}\text { Intrasplenic } \\
\text { Pressure } \\
(\mathrm{mmHg})^{3}\end{array}$ & $\begin{array}{l}\text { Portal } \\
\text { Vein }\end{array}$ & $\begin{array}{l}\text { Position } \\
\text { of Mass }\end{array}$ & $\begin{array}{l}\text { Size of } \\
\text { Mass }(\mathrm{cm})^{4}\end{array}$ \\
\hline 2 & 66 & $\mathbf{F}$ & Budd-Chiari & 7 & 31 & Patent & Right side & 3 \\
\hline 3 & 39 & $\mathbf{M}$ & Cryptogenic & 1 & 16 & Patent & Central $(\mathbf{L}>\mathbf{R})$ & 13 \\
\hline 4 & 55 & $\mathbf{F}$ & Myelofibrosis & 2 & - & Patent & Right side & 3 \\
\hline 5 & 55 & $\mathbf{M}$ & Postnecrotic & $1^{5}$ & 17 & Patent & Left side & 11 \\
\hline 7 & 69 & $\mathbf{F}$ & Cryptogenic & - & - & Thrombosed & Left side & 6 \\
\hline
\end{tabular}

Table Clinical details and radiological findings

${ }^{1}$ Or type of cirrhosis

${ }^{2}$ Measured from the time at which splenomegaly, oesophageal varices, or portosystemic encephalopathy were first noted.

${ }^{3}$ Normal pressure is $12 \mathrm{~mm}$ of mercury, or less.

'Transverse diameter on anteroposterior radiograph.

${ }^{5}$ Hepatitis nine years previously.

(fig 3). In two patients (nos. 2 and 4) the mass is small ( $3 \mathrm{~cm}$ across), situated just to the right of the spine and separated from the dome of the diaphragm by a gap of 1 to $2 \mathrm{~cm}$ (fig 4). In another two patients (nos. 5 and 7) the mass is larger, and situated to the left of the midline, adjacent to the diaphragm (fig 2). In the remaining three patients the mass is central, overlying the spine in the anterior projection and extending laterally beyond the vertebral column on each side (fig 1). In these three patients the mass is fusiform, with a vertical axis, and touches the dome of the diaphragm on each side.

In patients 1-4 both erect and supine films are available, and the size of each mass is the same in both positions. Patient 2 performed the Valsalva and Mueller manoeuvres, but again the size of the mass does not change. The azygos vein shadow is not enlarged in any of the patients, but tomography of the vein was not done. In the two patients who underwent portocaval anastomosis postoperative films are available. In patient 1 a supine film shortly after the operation shows no change in the size of the mass. In patient 6 no mass is discernible on a radiograph taken seven years postoperatively. Submucosal oesophageal veins were demonstrated by barium swallow in each patient, and in patient 1 the lobulated mass is seen displacing and indenting the lower oesophagus (fig 5).

Splenic venography shows that in each patient the posterior mediastinal mass is due to dilated portosystemic collateral veins (fig 6). In patients $1,3,5$, and 7 the mass is a tangle of dilated veins. In patient 6 the bulk of the mass is occupied by a single tortuous and massively dilated vein. In patient 2 there are just one or two tortuous veins (fig 7). Dilution of the contrast makes it difficult to determine the composition of the mass in patient 4 , but in no patient do the appearances suggest aneurysmal dilatation of a single vein. In patients 1-6 the portal vein is shown to be patent and the paraoesophageal collaterals are supplied from the left gastric vein, with a major contribution via the short gastric vein in patients 1 and 2 only. In patient 7 the portal vein is thrombosed and an aberrant vessel leads to the mediastinal collaterals.

In patient 4 the mediastinal collaterals drain into the pulmonary vein and he is patient 12 in the series of Shaldon, Caesar, Chiandussi, Williams, Sheville, and Sherlock (1961). His splenic venograms were reproduced in their paper. The drainage of the collaterals in the remaining patients was probably into the azygos and hemiazygos systems.

\section{Discussion}

We have described seven patients with portal hypertension in whom a lower posterior mediastinal mass is seen on the chest radiograph and shown to be due to dilated paraoesophageal veins. Patients 1,2 , and 6 have a long history of portal hypertension. Although patients 3-5 have only a short history, their liver function is compatible with asymptomatic disease of long duration. It is likely that many years are required for portosystemic collaterals to reach such a size that they can be seen on a plain chest radiograph. This finding is uncommon, being present in less than $5 \%$ of our patients with portal hypertension. Correct identification of paraoesophageal collaterals may avoid unnecessary thoracotomy (Sayer et al, 1954). Oesophageal transection performed for bleeding submucosal varices would be technically more difficult in the presence of paraoesophageal collaterals. Spontaneous haemorrhage from the latter has not, however, been recorded.

Venous masses must be differentiated from other causes of a posterior mediastinal mass. The commonest cause of a posterior mediastinal mass adjacent to the diaphragm is a hiatus hernia, but in 


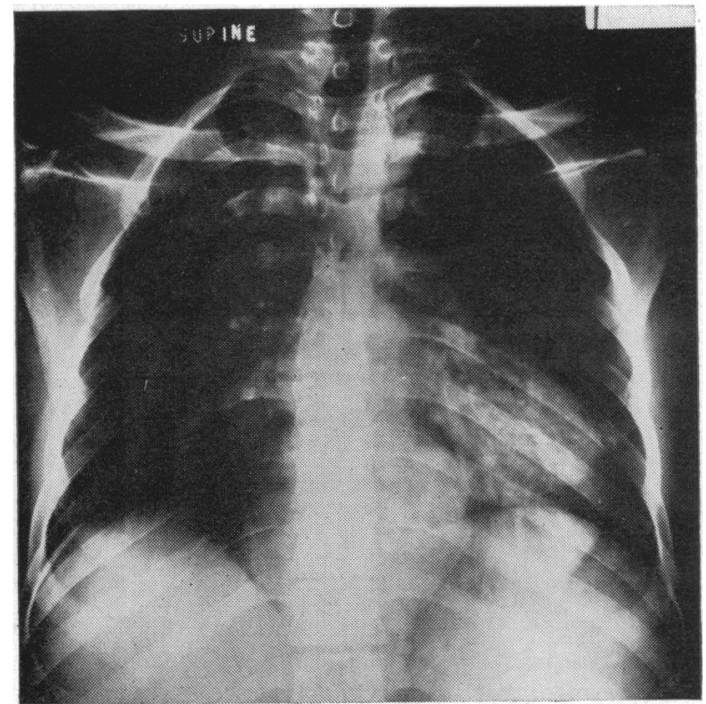

Fig 1 Patient 1. Supine anteroposterior chest radiograph shows a mass lying centrally in the lower posterior mediastinum, extending laterally beyond the vertebral column on each side.

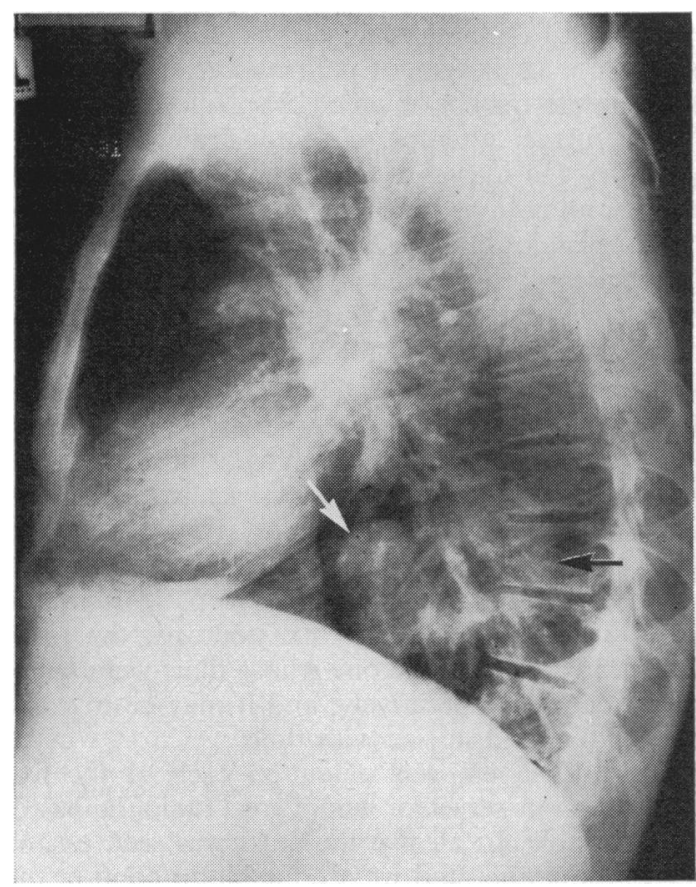

Fig 3 Patient 1. Left lateral chest radiograph shows the posterior mediastinal mass (arrowed).

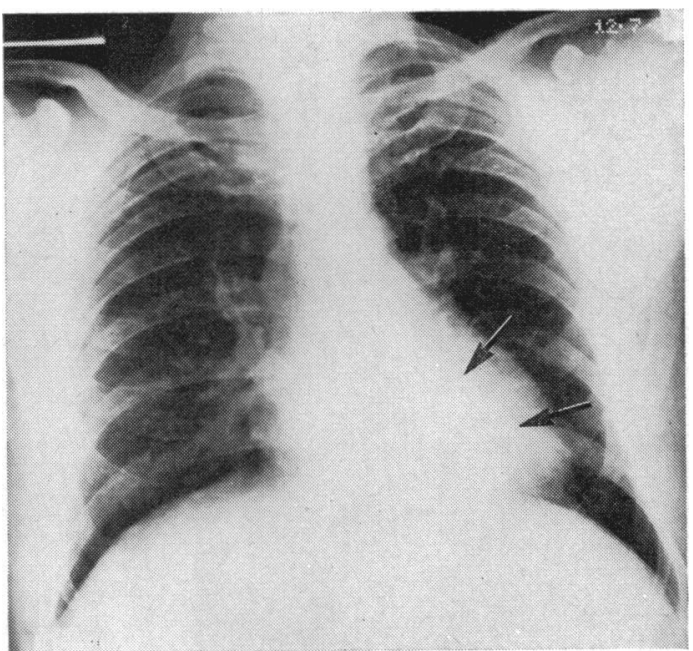

Fig 2 Patient 3. Erect posteroanterior chest radiograph. The venous mass is seen behind the cardiac shadow on the left side (arrowed).

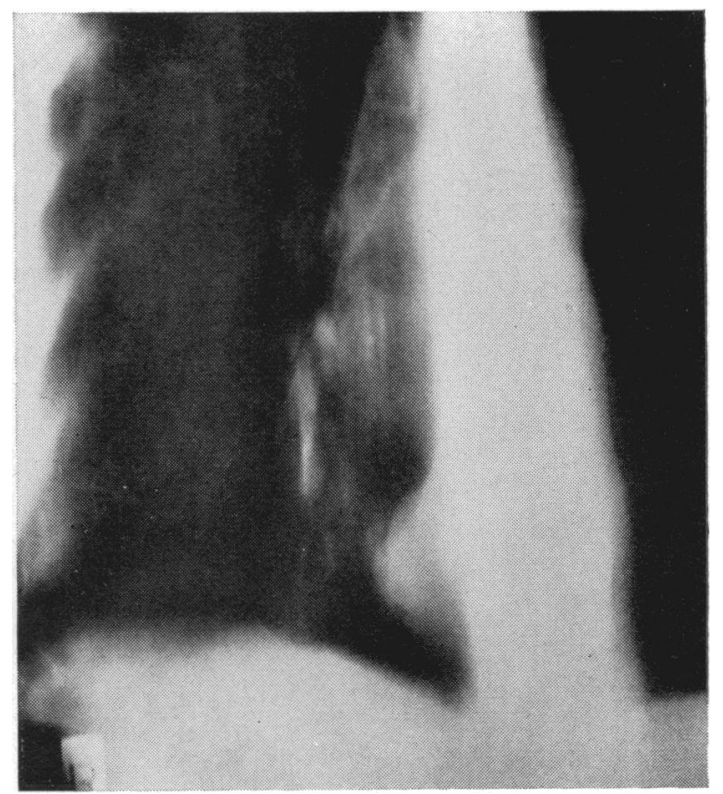

Fig 4 Patient 2. Tomography of the posterior mediastinum (without contrast medium) shows a mass on the right side, merging with the shadow of the vertebral column and separated from the dome of the diaphragm by a gap of $1 \mathrm{~cm}$. 


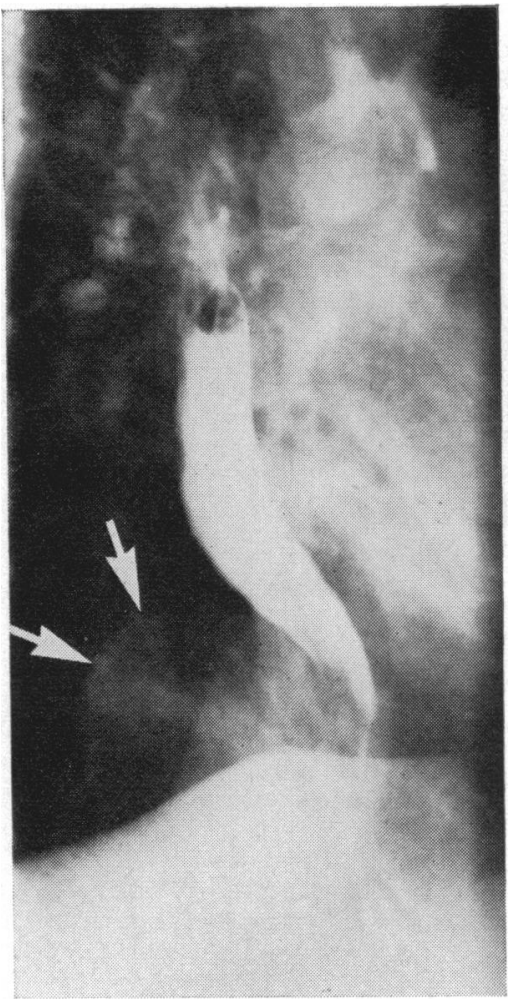

Fig 5

Patient 1.

Barium

swallow

shows

displacement

and indent-

ation of the

lower

oesophagus

by the venous

mass

(arrowed).

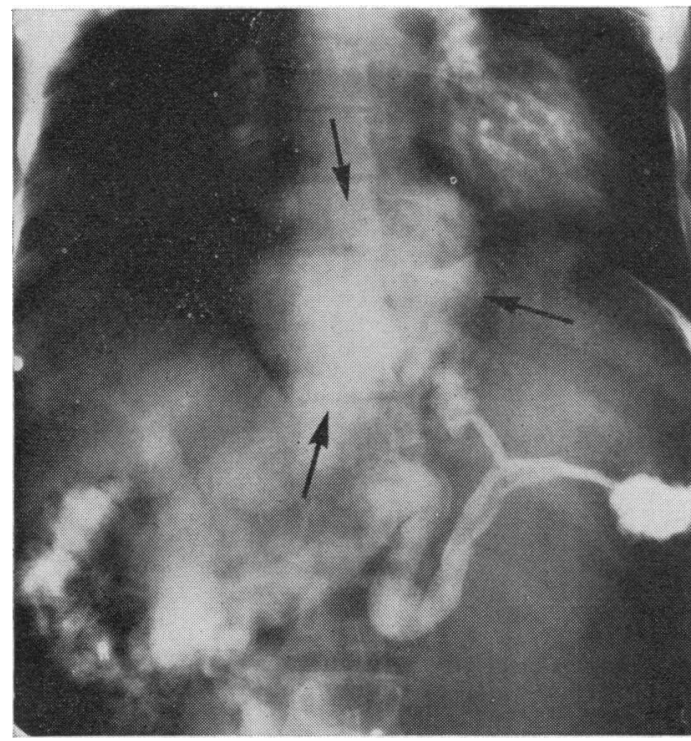

Fig 6 Patient 1. Splenic venogram shows a patent splenic vein and sparse portal vein radicles within a small liver. A short gastric vein and a grossly dilated left gastric vein supply perioesophageal veins (arrowed). The latter drained superiorly into the azygos and hemiazygos veins.

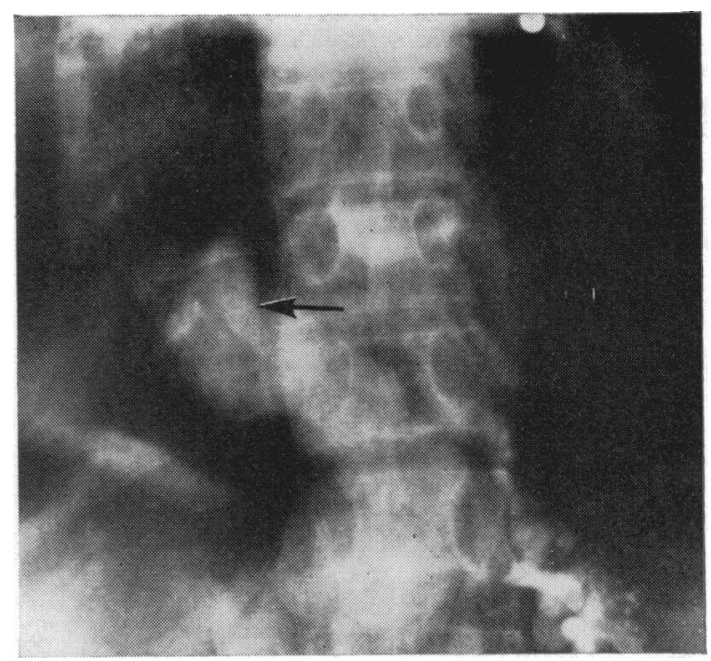

Fig 7 Patient 2. Splenic venogram. A lobulated right sided paraoesophageal varix fills (arrowed). A band-like shadow above the right hemidiaphragm is due to a pulmonary infarct.

patients with portal hypertension a round or lobulated shadow without air or fluid level suggests dilated venous collaterals. A barium swallow will exclude hiatus hernia, and all seven patients had evidence of submucosal varices in addition to paraoesophageal veins. Confirmation of the nature of the masses may be obtained by splenic venography.

In a further attempt to demonstrate the venous nature of the masses we have compared erect and supine radiographs in four of our patients. There is no discernible difference in size, probably because portal pressure exceeded hydrostatic pressure even in the erect posture. This test is therefore of no value in the diagnosis of a venous mass in our patients. Jonsson and Rian (1970), however, showed pseudotumoural oesophageal varices in two patients disappearing on assuming the erect posture. In one of these the intrasplenic pressure was equivalent to $22 \mathrm{~mm} \mathrm{Hg}$ (comparable with our series), but in the other this sign was positive only after a successful portocaval anastomosis. Of the two patients in our series who had portocaval anastomosis, the mass disappeared only in the one whose films were taken seven years postoperatively, and it may be that the mass diminished in size with time.

The portal vein was patent in each of the five patients in our series for whom erect radiographs are still available. In all five the mass was seen on the erect radiograph, and we are unable to confirm the suggestion made by Jonsson and Rian that persistence of the mass in the erect posture is an indication of portal vein thrombosis. Changes in size 
of the shadow with changes in intrathoracic pressure are characteristic of venous masses (Felson, 1960) but could not be demonstrated in patient 2. Bartram and Strickland (1971) also found this test unhelpful in the diagnosis of pulmonary varices.

We wish to thank Professor S. Sherlock for permission to report details of patients admitted under her care. We also thank the Department of Medical Photography of the Royal Free Hospital for the illustrations, and Miss Madeleine Skinner for preparing the manuscript.

References

Bartram, C., and Strickland, B. (1971). Pulmonary varices. Brit. J.
Radiol., 44, 927-935.

Campbell, H. E., and Baruch, R. J. (1960). Aneurysm of hemiazygos vein associated with portal hypertension. Amer. J. Roentgenol., 83, 1024-1026.

Doyle, F. H., Read, A. E., and Evans, K. T. (1961). The mediastinum in portal hypertension. Clin. Radiol., 12, 114-129.

Felson, B. (1960). Fundamentals of Chest Roentgenology, p. 9. Saunders, Philadelphia.

Jonsson, K., and Rian, R. L. (1970). Pseudotumoral esophageal varices associated with portal hypertension. Radiology, 97, 593-597.

Leigh, T. F., Abbott, O. A., Rogers, J. V., Jr., and Gay, B. B., Jr. (1954). Venous aneurysms of the mediastinum. Radiology, 63, 696-705.

Sayer, W. J., Parmley, L. F., Jr., and Morris, J. de L. S. (1954). Mediastinal tumor simulated by azygos phlebectasia. Ann. intern. Med., 40, 175-182.

Shaldon, S., Caesar, J., Chiandussi, L., Williams, H. S., Sheville, E., and Sherlock, S. (1961). The demonstration of porta-pulmonary anastomoses in portal cirrhosis with the use of radioactive Krypton (Kr $\left.{ }^{85}\right)$. New Engl. J. Med., 265, 410-414.

\section{The December 1974 Issue}

\section{THE DECEMBER 1974 ISSUE CONTAINS THE FOLLOWING PAPERS}

Identifying toxic fractions of wheat gluten and their effect on the jejunal mucosa in coeliac disease A. S. DISSANAYAKe, D. W. JeRrome, R. E. OFFORD, S. C. TRUELOVE, AND R. WHITEHEAD

Gluten-sensitive enteropathy: Synthesis of antigliadin antibody in vitro $\mathrm{z}$. MYRON FALCHUK, AND WARREN STROBER

Indices of granulocyte activity in inflammatory bowel disease S. P. KANE, A. V. HOFFBRAND, AND G. NEALE

Effects of sulphasalazine (Salazopyrin) on faecal flora in patients with inflammatory bowel disease BERYL WEST, R. LENDRUM, M. J. HILL, AND GEOFFREY WALKER

The relative importance of the factors involved in the absorption of Vitamin $E$ in children D. P. R. MULLER, J. T. HARRIES, AND J. K. LLOYD

Studies of lactic dehydrogenase content in rectal mucosal biopsies P. S. HUNT, P. M. DENNIS, P. JABLONSKI, S. K. KHOO, L. MCCLEOD, H. D. P. THOMSON, AND J. MCK. WATTS
Electrical potential difference and absorption of water, sodium, and potassium by the terminal ileum of ileostomy patients J. PRADO p. de MORAES-FILHO, C. SALAS-COLL, LAURIE BLENDIS, AND C. J. EDMONDS

Impairment of 'ileostomy adaptation' in patients after ileal resection G. L. HILL, W. S. J. MAIR, AND J. C. GOLIGHER

Use of bumetanide in the treatment of ascites due to liver disease P. J. A. MOULT, M. R. LUNZER, D. B. TRASH, AND S. SHERLOCK

Coagulation factor concentrate in the treatment of haemorrhagic diathesis of fulminant hepatic failure B. G. GAZZARD, M. L. LEWIS, G. ASH, C. R. RIZZA, E. BIDWELL, AND ROGER WILLIAMS

Effects of lactulose and other laxatives on ileal and colonic $\mathrm{pH}$ as measured by a radiotelemetry device R. L. BOWN, J. A. GIBSON, G. E. SLADEN, B. HICKS, AND A. M. DAWSON

Progress report

The circulation of the small bowel mucosa

Notes and activities 